\title{
A Metamodel for Evaluating Enterprise Readiness in the Context of Industry 4.0
}

\author{
Josef Basl ${ }^{1, *}$ and Petr Doucek ${ }^{2}$ (]) \\ 1 Department of Information Technologies, University of Economics, 13067 Prague 3, Czech Republic \\ 2 Department of System Analysis, University of Economics, 13067 Prague 3, Czech Republic; doucek@vse.cz \\ * Correspondence: basl@vse.cz; Tel.: +420-224-095-459
}

Received: 8 January 2019; Accepted: 22 February 2019; Published: 28 February 2019

\begin{abstract}
This article analyzes the available readiness indexes and maturity models applied for trends designated as "4.0", with a focus on Industry 4.0, primarily within the countries of Europe. Based upon it, the available indexes and maturity models are organized into the individual layers of the metamodel; a proposal for this metamodel is this article's main output. Simultaneously, as-yet-uncovered places for the development of existing maturity models, as well as space for further detailed research into the application of Industry 4.0 in theory and in practice, are identified on the basis of this metamodel.
\end{abstract}

Keywords: Society 4.0; Industry 4.0; maturity model; readiness index; Industry 4.0 readiness; cyber security risk

\section{Introduction-Industry 4.0 Trends Are Part of a Society-Wide Digitalization}

The further digitalization, robotization, and automation of manufacturing are the main goal-points of the trends that are collectively being called Industry 4.0. This closed life cycle for products and services is leading to a conception termed the "Circular Economy." Its relations to Industry 4.0 are developed in detail, e.g., in [1]. When we consider how highly relevant the trends termed "Industry 4.0" are, we have to admit that the beginnings of the incorporation of automation elements into industrial practice date back to not merely this decade, but rather almost 40 years ago, in the form of, e.g., FMS (Flexible Manufacturing Systems) [2]. Furthermore, already within CIM (Computer Integrated Manufacturing) [3], we can find the digitalization of the production system and the product. Speaking in retrospect today, we call this period of the last century the "third industrial revolution," while describing the current phase as the subsequent one-the "fourth industrial revolution". The word "revolution" is fully justified here, because besides merely encompassing technical areas, the " 4.0 trends" affect most areas of society; for example, Farming 4.0, Health 4.0, or AlmaMater 4.0.

Various authors are already coming to terms with this fact in various ways today $[4,5]$. Some are introducing the term "5th Industrial Revolution," or "Industry 5.0" [6,7]. Others-including the authors of the present article-would instead make do with the term "information society" to describe our current society. An information society can, of course, have varying significant and independently evaluable stages during its further development. This approach corresponds with an approach that incorporates a greater distance and detachment. Among other things, certain historians, for example, are moving towards such a perception of important historical milestones as a part of a greater whole.

At present, it is beginning to become unnecessary to primarily focus on awareness-raising regarding what 4.0 trends are and what they can bring. These trends are, at least in certain respects, already advancing quickly within many enterprises, and furthermore, their dynamics correspond to the high pace of change overall today. Meanwhile, these are not technological changes alone; they also include further changes, e.g., to demographics and the climate. Thus, the question today 
is not "whether," but "when," i.e., how fast 4.0 trends will penetrate into the day-to-day lives of enterprises—and beyond them into society overall.

Various readiness indexes and maturity models can help companies to make easier, and also faster, decisions concerning the question of in which areas they should build up Industry 4.0, and at what tempo. Both of these, meanwhile, indicate not only a company's own position, but also the positions of its competition. At present, attention is shifting towards tasks connected with the execution of needed changes and towards specifying the expectations other than merely profit that are connected with their deployment. For example, achieving the highest possible flexibility and increasing the availability of products and services, along with further decreasing costs, lowering resource consumption, and decreasing the environmental impact, etc.

The goal of the present article is to analyze and summarize readiness indexes and maturity models, compare their basic characteristics, and incorporate them into a metamodel that we propose. This metamodel organizes selected maturity models and readiness indexes relative to each other, while simultaneously identifying areas where there is potential for further research. Last but not least, the proposed metamodel is an important guideline for the development of subsequent detailed analyses of areas such as security—which will play a very important role in enterprises' readiness levels.

\section{Methodology and Data Collection}

The fundamental methodology used in this article is that of studying subject literature and comparing the facts thus found, both among each other and with our mental models in the area of Industry 4.0. The basic set of data that was used for comparing Industry 4.0 models comprised publications. From among monographs, meanwhile, it comprised the outputs of prestigious publishers, located primarily in Germany, the USA, and other countries where the concept that corresponds to the ideas of Industry 4.0 is under constant development.

The outputs obtained from working to answer our questions while studying the topic literature can be divided into two main categories. The first of these is the methodological category: how to look at models of Industry 4.0, and through which criteria to classify and evaluate views of them. Here, the output is a dimensional view, i.e., dividing up views of Industry 4.0 model evaluations by individual dimensions. These dimensions are listed in Section 4 . The rating scales within the dimensions closely tie into these dimensions.

Most important among the other outputs, meanwhile, is the table in Section 4.2, which contains a classification of Industry 4.0 maturity models and also identifies opportunities for the further expansion of research.

When composing them, we had to take into account the fact that the available readiness assessments and models of maturity for Industry 4.0, and more generally for digitalization, reflect the trends in recent years, and thus a set of roughly two dozen different maturity models serves for the purposes of this article. Meanwhile, the readiness assessments are based upon one of two approaches. The first of these is the collecting of a large quantity of data from the given set of evaluated entities (e.g., for readiness indexes, this is NRI (Networked Readiness Index), GII (Global Innovation Index), or GCI (Global Competitiveness Index)). The evaluated indicators are then scored and, based on their overall results, rankings of the evaluated entities or entire countries are constructed. The second of them is the use of an evaluation method that only assesses the situation for a single entity (enterprise), based on a pre-formulated maturity-model scale, and provides a value-a rating-for the given enterprise (very often on a scale from 1 to 5 , expressed, for example, in words ranging from beginner to expert, or in some cases master, etc.)

We have integrated the following things within our work on creating the proposed metamodel: 
- A view of the present with future development termed "5.0". The inclusion of the 0th level in the metamodel corresponds with this;

- A view of the "macro," i.e., state, level, as well as of the "micro," i.e., enterprise level. Levels 1 and 2 correspond to this, or more precisely, these two along with levels 3 and 4 (for the "macro" level) and 4 through 6 (for the "micro" level) as well.

This model has also produced the prerequisites for a basic framework into which more detailed readiness models from level 6 onwards can be placed. An elaboration for the enterprise/technologies area and one for the enterprise/IT area-dimension are two examples of such models. Meanwhile, examples of sub-dimensions of the enterprise/IT area may include, e.g., applications in the ERP systems category that correspond to the seventh level of the metamodel for this meaning-dimension, for an enterprise with appropriate attributes.

It follows from the contents of the available, analyzed sources that they all have one assumption in common: that all of the current digitalization trends share classifiability as "Industry 4.0". However, this unfortunately need not necessarily be the case, and the approaches actually do not share this trait. It would also be appropriate to also take the fact that not even Industry 4.0 is the final stage of development-neither for enterprises nor for technologies-into account in any view of current evaluation approaches.

\section{Theoretical Background-An Overview of the Readiness Indexes and Maturity Models for Evaluating Enterprises' Readiness for Industry 4.0}

A study of the literature was our fundamental starting point for composing an overview of the available evaluation frameworks. An analysis of these is provided in the chapters below.

\subsection{Enterprises' Industry 4.0 Readiness Based on Readiness Indexes}

An enterprise always exists within a particular environment, which in many cases preconditions, and in many other cases even predetermines, its digitalization and its general ability to innovate. Thus, we can look at the evaluation of enterprises not only from the "micro" standpoint, i.e., that of the given enterprise, but also-necessarily in fact-from the standpoint of its broader context and its links to it. Among other things, one of the individual dimensions of the German RAMI 4.0 reference model for Industry 4.0, mentioned frequently by many authors, also contains this link within itself [8,9]. Within this "macro" view, we are viewing the whole of society, or individual nations. Multiple significant readiness indexes have long existed in this respect (Table 1), such as:

- $\quad$ NRI (Networked Readiness Index) [10];

- GII (Global Innovation Index) [11];

- GCI (Global Competitiveness Index) [12].

And further

- OECD scoreboard [13].

For direct evaluations of Industry 4.0, meanwhile, this concerns:

- The Industry 4.0 Readiness Index from Roland Berger [14].

These "macro" readiness evaluations more generally point towards overall prerequisites for digitalization in a given country, including its readiness for innovation, which are equally important for the development of Industry 4.0. One factor shared in common by these "macro" evaluations is a large number of countries analyzed, as well as a large scope (quantity) for the evaluated criteria. In many cases, the fact that these indexes form long-term time series (starting in 2002, for example, in the case of NRI) - rather than only having appeared in connection with Industry 4.0 -is another factor. 
Another interesting fact from the methodological standpoint is that they typically produce a single value achieved by a given country within the given readiness-evaluation index, and thereby provide that country with feedback on its placement relative to other countries. This is not, therefore, an absolute rating, but rather a relative placement within an evaluated set of economies, with the possibility of comparing its trends over time.

The term "Society 4.0 " likewise provides an overview of a nation and its economy alongside the above-mentioned indexes within " 4.0 development." That is, within "Society 4.0," alongside "Industry 4.0," one can find further "4.0" areas as well, such as the above-mentioned "Farming 4.0," focused on agricultural food production, and, e.g., public services such as "Health 4.0" and "Alma Mater 4.0." Last but not least, there is e-Government (or "Government 4.0"), as well as concepts that are overall marked with the keyword "smart." Trends such as smart cities, smart homes, the smart grid, etc., can serve as examples here, with smart factories, meanwhile, being an example from industry. Within this article, the following description goes on to focus on the area of Industry 4.0 alone.

Table 1. The main readiness indexes.

\begin{tabular}{ccccc}
\hline $\begin{array}{c}\text { Index } \\
\text { Abbreviation }\end{array}$ & Index Name & $\begin{array}{c}\text { Evaluating } \\
\text { Authority }\end{array}$ & $\begin{array}{c}\text { Number of Individual } \\
\text { Indicators }\end{array}$ & $\begin{array}{c}\text { Number of Countries } \\
\text { Evaluated }\end{array}$ \\
\hline NRI & $\begin{array}{c}\text { Networked Readiness } \\
\text { Index }\end{array}$ & $\begin{array}{c}\text { WEF World } \\
\text { Economic Forum }\end{array}$ & 51 & 139 \\
\hline GII & Global Innovation Index & $\begin{array}{c}\text { Cornell University, } \\
\text { INSEAD, WIPO }\end{array}$ & 200 \\
\hline OECD score-board & $\begin{array}{c}\text { Science, industry and } \\
\text { technology Scoreboard }\end{array}$ & OECD & 31 \\
\hline RBI & $\begin{array}{c}\text { RB Industry 4.0 } \\
\text { Readiness Index }\end{array}$ & Rolland Berger & $\begin{array}{c}\text { The size of the industry's } \\
\text { share in the GDP forms the } \\
\text { evaluation's second axis } \\
\text { alongside this RB Index itself }\end{array}$ \\
\hline
\end{tabular}

\subsection{Enterprises' Industry 4.0 Readiness Based on Maturity Models}

For evaluations on the enterprise level, that of individual enterprises, the situation differs from that on the "macro" level. Here, no comparisons of a large number of enterprises are necessarily involved, but rather evaluations, and often self-evaluations, regarding the stage of maturity at which a given enterprise lies. This may be why maturity models dominate at this micro level (in contrast to the macro level, where readiness indexes dominate).

These maturity models are produced at a variety of sites—on academic soil, at $\mathrm{n}$ consulting companies, and at various levels of government. Twenty-two models were used for the drafting of this article. Through a review of the literature, the following models were obtained and then analyzed:

1. RAMI 4.0 (The Reference Architectural Model Industry 4.0) from BITCON VDI/VDE, ZVEI (Germany) [15];

2. Industry 4.0 Component Model-derived from RAMI 4.0 and oriented on information technology (Germany) [16];

3. IMPULS (Industry 4.0 Readiness) from VDMA and RWTH (Germany) [17];

4. SIMMI 4.0 (System Integration Maturity Model Industry 4.0) from TU Dresden and TU Heilbronn (Germany) [18];

5. M2DDM (Maturity Model for Data Driven Manufacturing) from University Stuttgart (Germany) [19];

6. Digitalization Degree of Manufacturing Industry from Friedrich-Alexander University Erlangen (Germany) [20];

7. Industry 4.0 Maturity Model from the Austrian Fraunhofer and the Austrian Vienna University of Technology (Austria) [21]; 
8. Reifegradmodell Industrie 4.0 developed at the Fachhochschule Oberösterreich in collaboration with Mechatronik-Clusters (Austria) [22];

9. Roadmap Industry 4.0 from University Caphenberg (Austria) [23];

10. Digital Maturity Model developed by the Swiss University of St. Gallen, in collaboration with Crosswalk (Switzerland) [24];

11. DREAMY (The Digital Readiness Assessment Maturity Model) from Confindustria, Assoconsult and the University of Politecnico di Milano (Italy) [25];

12. Industry 4.0 Readiness Evaluation for Manufacturing Enterprises from Academy of Science Hungary (Hungary) [26];

13. Industrie 4.0 MM (Assessment model for Industry 4.0) from University Ankara (Turkey) [27];

14. An Industry 4 readiness assessment tool developed at the University of Warwic (The United Kingdom) [28];

15. Stage maturity model in SME towards Industry 4.0 [29];

16. Industry 4.0/ Digital Operation Self-Assessment from Price Waterhouse Coopers [30];

17. APM Maturity Model (Asset Performance Management Maturity Model from Capgemini) [31];

18. The Connected Enterprise Maturity Model from Rockwell Automation [32];

19. Industrie 4.0 Maturity Model from Acatech Studie [33];

20. Firma4.cz from the Ministry of Industry and Trade of the Czech Republic [34];

21. Pathfinder 4.0 [35];

22. The Singapore smart industry readiness index developed by the Singapore Economic Development Board, Singapore [36].

From this overview, it is clear that the vast majority of these models were produced in the last two years, and moreover at a very diverse spectrum of workplaces, with examples being available throughout Europe.

\section{An Analysis of the Available Models and a Proposal for a Metamodel for Enterprises' Industry 4.0 Readiness}

One thing that is characteristic of the theoretical concepts of Industry 4.0 is the measurement of the achieved level of maturity in various areas of information technologies' penetration into enterprise processes.

\subsection{The Main Evaluating Dimensions and Scales Found in the Available Models}

When evaluating analyzed models of enterprises' maturity for Industry 4.0, one must take into account the following attributes:

- The scope of the evaluation - this is usually an enterprise-wide scope, but it can also be a focus on a particular area, such as enterprise technologies, or perhaps on only enterprise IT and its information systems;

- Dimensions of the evaluation - usually, these dimensions are related to the evaluation's scope (see above), but they are also related to the depth of the evaluation, i.e., its amount of detail. Where a high-detail evaluation focused exclusively on IT is involved, a large number of component attributes can then be taken into account;

- Evaluation scale- this sets the scope, degrees, and approach to enterprise maturity in the given dimension, or to its evaluation of the enterprise overall. 
The main findings that we have acquired from the available maturity models show us that these models are very comprehensive, and yet generally do not contain a detailed view, focusing instead on enterprise-wide dimensions at the level of an enterprise's top management, such as:

- Strategy;

- Leadership;

- Corporate culture;

- Human resources;

- Technology.

Most models contain a "Technology" dimension, but its conception differs among them. Alongside information technology, it also tends to contain technology for manufacturing, assembly, and logistics. On the other hand, information technology in an enterprise is sometimes spread out into other dimensions, such as:

- Product digitalization;

- Process digitalization;

- Digital management.

In this context, it is surprising that, although the models we have analyzed do mention the attributes of cross-sectional sub-dimensions, such as quality or the above-mentioned security dimension, they only rarely elaborate them deeper. This means, to put it otherwise, that these attributes can be a part of such dimensions of meaning as production, logistics, etc., but it is not typical to perceive them as independent dimensions of meaning. If we were to think of this fact as a matrix, then indeed dimensions of meaning would form one of its sides, while cross-sectional dimensions would form the other.

The scales that are used for evaluation are largely based on the principle of evaluating levels that are known from the traditional conception of maturity models, but digitalization scales and evaluations of an enterprise as a whole are used by some of them as well.

From the standpoint of evaluating the specialization of Industry 4.0 maturity models, the models we have evaluated are scattered along a wide spectrum on the range: from a model being focused on an entire enterprise all the way to it being focused specifically on that enterprise's digitalization-concentrating on its information technologies. We could thus identify within maturity models an analytical tool for evaluating an enterprise's current state of Industry 4.0 readiness and maturity, but some models also contained a guide to upcoming steps, within a certain "roadmap" for transition to this enterprise conception.

Overall, our analysis on the macro and then on the micro level, i.e., on the level of readiness indexes and further of maturity models, has shown that:

- in the area of evaluation, no sector-wide solutions have been fully elaborated to date (e.g. for automotive, food, or chemistry), and there are no solutions for various types of enterprises or that take into account the specifics of small and medium enterprises (SME);

- attributes of the IT dimension that are key for digitalization are not elaborated in the individual models;

- cross-sectional dimensions such as, e.g., the issue of security, which can also represent new risks in the implementation of Industry 4.0, are not elaborated in the models;

- many dimensions are not disjunct, but instead internally mutually repeat a view of a higher enterprise level, in the spirit of a fractal approach [37];

- it would be appropriate to fill in orders and degrees within the evaluation scales, e.g., based on the work of professor Valenta, who works with null and even negative dimensions [38];

- last but not least, certain states in principle cannot be maturity states, but only binary states. Legislative recommendations concerning GDPR rules and the upholding of norms for Industry 4.0 are examples here. 
Our analysis also highlighted the fact that the question of whether it is better to approach and view Industry 4.0 via a readiness index or instead via a maturity model is the wrong question. This is because these two approaches are not in conflict, but rather, each one provides important information, while drawing upon different data and conducting different processing of that data.

\subsection{Proposal for a Metamodel for Evaluating Enterprise Readiness Within Industry 4.0}

We have worked the results we obtained from our analysis into a proposal for a metamodel of the evaluation of enterprise readiness in the context of Industry 4.0. The readiness indexes and models of maturity for Industry 4.0 that were mentioned in this article and that are the subject of the analysis can be organized together into a single shared metamodel that pictures them, including their individual levels and attributes.

The levels are depicted in individual columns and represent the model's top row. The attributes, meanwhile, are in the corresponding row of the given level, in the corresponding column.

The model has seven levels overall, with each level gradually providing more details than the previous one:

Level 1-initial level a current view of society (Society 4.0);

Level 2-an area of society (Industry 4.0 is one of them, Farming 4.0, Health 4.0 et al. are the other);

Level 3-a sector within an individual area of society (for Industry 4.0, these can be, e.g., enterprises within the automotive, chemistry, electronics, or food industries; special attention should be paid to small and medium enterprises);

Level 4-an enterprise as a whole;

Level 5-an area within an enterprise, which based on the analysis of models, could mostly be:
a. technologies,
b. human resources,
c. strategies,
d. processes,
e. data,
f. security, etc.;

Level 6-dimensions within the enterprise area. For the above-mentioned area of technology:

a. information technologies,

b. manufacturing technologies (additive manufacturing, 3D prints, predictive maintenance, and robotization of assembly and welding),

c. handling and warehousing technologies (automated vehicles, drones, and handling robots);

Level 7-a sub-dimension within an individual dimension of an area of an enterprise, e.g., a detailed elaboration of information technologies can provide maturity-model views for:

a. Sub-dimensions of meaning: e.g., application software to support planning (such as ERP, MES, or APS), decision-making support (BI, CI, AI), and support for sharing information, product, and production-system digitalization (CAD, PLM);

b. Cross-sectional sub-dimensions: e.g. security, quality, connectivity, and integrability. 
There could be separate maturity models under this level 7 for sub-dimensions, like:

1. meaning-oriented sub-dimensions:
ERP applications,
$\bigcirc \quad$ production planning,
- workplace ergonomics;

2. and cross-sectional sub-dimensions:
security,
maintenance,
connectivity,
$\bigcirc \quad$ data and processes.

Table 2 gives a clear, overall view of the individual mutually connected levels of our metamodel of enterprises' readiness for Industry 4.0. Additionally, it has a "horizontal" line indicating the gradual increasing of detail for the view of an enterprise's readiness. Its "core," meanwhile, lies in individual maturity models. However, as the above-mentioned analysis has shown, these do not yet cover in detail the areas of IT, enterprise architecture, security, and new risks.

Thus, new requirements for all forms of integration (horizontal integration, vertical integration, and process and data integration) likewise lack a detailed description. Last but not least, potential new demands placed upon management methods, such as those that arose, for example, at the beginning of the deployment of extensive ERP systems in the early 1990s, when these deployments called forth a wave of process management connected with process mapping and, above all, re-engineering, have not been mapped out to date. 
Table 2. A metamodel of an enterprise's readiness for Industry 4.0 within Society 4.0.

\begin{tabular}{|c|c|c|c|c|c|c|c|}
\hline $\begin{array}{c}\text { Number of } \\
\text { Metamodel Level }\end{array}$ & 1 & 2 & 3 & 4 & 5 & 6 & 7 \\
\hline $\begin{array}{c}\text { Name of } \\
\text { Metamodel Level }\end{array}$ & Society & Area of society & $\begin{array}{c}\text { Branch of area of } \\
\text { society }\end{array}$ & Enterprise & Area of enterprise & $\begin{array}{c}\text { Dimension of enterprise } \\
\text { area }\end{array}$ & $\begin{array}{c}\text { Subdimension of } \\
\text { enterprise area }\end{array}$ \\
\hline Main trends & Society 4.0 & $\begin{array}{l}\text { Industry } 4.0 ; \\
\text { Farming 4.0; } \\
\text { Health 4.0; } \\
\text { Alma Mater 4.0; } \\
\text { and other }\end{array}$ & $\begin{array}{l}\text { Automotive; } \\
\text { Electronic; } \\
\text { Food industry; } \\
\text { etc. }\end{array}$ & Industry 4.0 & $\begin{array}{c}\text { Technology; } \\
\text { Strategies; } \\
\text { Corporate culture; } \\
\text { Human resources }\end{array}$ & $\begin{array}{c}\text { IT (Information } \\
\text { technology); } \\
\text { Manufacturing } \\
\text { technologies (3D); } \\
\text { Assembly and handling } \\
\text { technologies (robots) } \\
\end{array}$ & $\begin{array}{l}\text { ERP (Enterprise } \\
\text { information } \\
\text { systems) }\end{array}$ \\
\hline $\begin{array}{l}\text { Main readiness } \\
\text { indexes and } \\
\text { maturity models } \\
\text { within the given } \\
\text { level of the model }\end{array}$ & $\begin{array}{l}\text { NRI index; } \\
\text { GCI index; } \\
\text { Roland Industry } \\
\text { 4.0 Readiness } \\
\text { index }\end{array}$ & $\begin{array}{l}\text { Maturity models } \\
\text { for areas such as } \\
\text { Industry } 4.0 \text { or } \\
\text { Farming } 4.0 \text { etc. }\end{array}$ & NA * & $\begin{array}{c}\text { RAMI 4.0; } \\
\text { SIMMI 4.0; } \\
\text { IMPULS; } \\
\text { DDMI; } \\
\text { M2DDM; } \\
\text { and other } \\
\text { analyzed models } \\
\end{array}$ & $\begin{array}{c}\text { Degrees from } \\
\text { Basic } \\
\text { Digitalization to } \\
\text { Optimized Full } \\
\text { Digitalization or } \\
\text { from Outsider to } \\
\text { Top Performer }\end{array}$ & $\mathrm{NA}^{* *}$ & $\mathrm{NA}^{* * *}$ \\
\hline Note & & $\begin{array}{l}\text { Other trends are } \\
\text { connected with the } \\
\text { term "smart": } \\
\text { smart city, smart } \\
\text { grid, smart home, } \\
\text { and smart parking }\end{array}$ & $\begin{array}{c}\text { No suitable models } \\
\text { focused solely on a } \\
\text { particular sector or } \\
\text { branch of enterprises } \\
\text { have been published } \\
\text { so far } \\
\end{array}$ & $\begin{array}{l}>20 \text { Maturity } \\
\text { evaluation } \\
\text { models—see } \\
\text { Section } 4\end{array}$ & & $\begin{array}{l}\text { IT technology can also be } \\
\text { divided up into: } \\
\text { horizontal integration; } \\
\text { vertical integration; } \\
\text { digital twins; } \\
\text { artificial intelligence }\end{array}$ & \\
\hline
\end{tabular}

*: Room for further research of readiness for selected branch; **: Room for further research of technology readiness; ***: Room for detailed research of ERP readiness model, e.g. 


\subsection{The Growing Importance of Security-Type Cross-Sectional Dimensions}

The analyzed models also still pay too little attention to cross-sectional topics. For the future, the most important attributes of the enterprise dimension will include, for example, the issue of security risks connected with the use of information and communication technologies.

In his book dedicated to Industry 4.0, Marik states [39], "The safety and reliability of Industry 4.0 systems must be understood in a comprehensively systematic way-from data and communication security at the lowest level, on through infrastructure reliability and security, on out to global system security at the level of manufacturing plants or chains of them, including the upholding of individuals' information privacy and of intellectual property rights".

Despite these proclamations, he devotes very little space to security itself. This dimension is among those that are overlooked in the models we have studied. Cyber-security risks represent a new challenge, as well as new risks with which we will have to come to terms with in the future. Among the greatest of these is the danger of the creation of a false virtual reality-a digital image of an enterprise system in which the information flows will not reflect actual material or energy flows. This type of phenomenon can even lead to the collapse of an entire enterprise system, and also to a loss of trust in enterprise information systems and the data stored within them.

The cyber-security risks addressed in the conception of Industry 4.0 security are mainly tied to questions that are very narrowly technological— to the wireless transmission of data among manufacturing and monitoring devices and to the individual sensors used for implementing the Industrial Internet of Things (IIoT), and in some cases, to personal data protection issues. The two main areas, IIoT vs. data, have very different natures. While secure IIoT communication is a topic for new research and the application of new technologies, the area of personal data security tends to be more connected with the areas of process management and modeling. If we are to analyze the areas within IIoT communication in more detail, this finds us running into the following areas of cyber-security risks for communication among individual devices:

- The security of the integrity of transferred and processed data influences the trustworthiness and completeness of the data provided. The provider strives to ensure full data integrity such that the integrity of the data during transfer cannot be disrupted in any way;

- Jamming. There are two different aspects to this phenomenon. One of them is that of the jamming of an individual sensor or device. This fact is often very closely connected with the frequency band for data transfer, which can naturally disrupt the device. What is very important, however, is that these devices are not be easy to jam. The second, significantly more important, defense is against the jamming of the entire communication network. This kind of incident can have fairly large effects on an enterprise as a whole and on its outputs.

Protection of an enterprise information system overall and of its assets within an information security management system (ISMS), meanwhile, is an entirely different dimension. It is always the case that a system's security is only as strong, or as weak, as its weakest link.

The reliability and trustworthiness of the data that is gathered using sensors and stored in data warehouses or lakes are further dimensions of today's comprehensive conception of security. Here, the problem's contours are as follows: if a party happens to receive data that is distorted in some way (a defective sensor, an imprecise temperature reading, etc.; for example, a sensor's sensitivity is lower than is required, a sensor has suffered wear and tear, or a drop in battery voltage has caused imprecise measurements), its control system with firmly set, required values then guides the control system in entirely the wrong direction. When artificial intelligence is also involved, this can even lead to the destruction of the entire system.

\section{Conclusions and Final Recommendations}

At present, the term 4.0 is being given so much attention that it is even too much, as we can observe in conference topics and frequencies. Even though the current digitalization trends are very striking, 
and their effect on all areas of human activity are undeniably large, a certain "distance" or detachment is necessary. The technical sciences are better able to evaluate the matter within its exponential growth than the social sciences are: the latter have been using, for example, the somewhat absolutist designation "postmodern society" since back in the 1990s [40]. It can also be expected that sustainable development and "green IT" [41], which dominated among the main topics at prestigious events as recently as at the start of this decade, and which are both related to information and communication technologies, have only temporarily been placed on the back burner.

Author Contributions: Both authors wrote and revised the paper. J.B. evaluated existing models and formulated visions of Industry 4.0 development. P.D. realized the sources overview and formulated parts relating to security topics.

Funding: This research received external funding from the "Czech Science Foundation project GAČR 17-02509S" and support from the project Faculty of Informatics and Statistics IP400040

Acknowledgments: The paper was processed with contributions from the Czech Science Foundation project GAČR 17-02509S and with support from an institutional-support fund for long-term conceptual development of science and research at the Faculty of Informatics and Statistics of the University of Economics, Prague (IP400040).

Conflicts of Interest: The authors declare no conflict of interest.

\section{References}

1. Tseng, M.-L.; Tan, R.R.; Chiu, A.S.F.; Chien, C.-F.; Kuo, T.C. Circular Economy meets Industry 4.0: Can Big Data Drive Industrial Symbiosis? Resour. Conserv. Recycl. 2018, 131, 146-147. [CrossRef]

2. Tempelmeier, H.; Kuhn, H. Flexible Manufacturing Systems: Decision Support for Design and Operation, 1st ed.; John Wiley \& Sons, Inc.: New York, NY, USA, 1993.

3. Scheer, A.-W. CIM Computer Integrated Manufacturing: Der Computergesteuerte Industriebetrieb, 4th ed.; Springer: Berlin/Heidelberg, Germany, 1990.

4. Keidanren-Japan Business Federation. Toward realization of the New Economy and Society-Reform of the Economy and Society by the Deepening of "Society 5.0". Available online: http:/ / www.keidanren.or.jp/ en/policy/2016/029_outline.pdf (accessed on 10 December 2018).

5. Cartwright, P. Manufacturing Gets Personal in Industry 5.0. Available online: https:/ /www.raconteur.net/ technology /manufacturing-gets-personal-industry-5-0 (accessed on 10 December 2018).

6. Sachsenmeier, P. Industry 5.0-The Relevance and Implications of Bionics and Synthetic Biology. Engineering 2016, 2, 225-229. [CrossRef]

7. Özdemir, V.; Hekim, N. Birth of Industry 5.0: Making Sense of Big Data with Artificial Intelligence, "The Internet of Things" and Next-Generation Technology Policy. OMICS J. Integr. Biol. 2018, 22, 65-76. [CrossRef]

8. Wang, Y.; Towara, T.; Anderl, R. Topological Approach for Mapping Technologies in Reference Architectural Model Industrie 4.0 (RAMI 4.0). In Proceedings of the World Congress on Engineering and Computer Science 2017, San Francisco, CA, USA, 25-27 October 2017; pp. 982-990.

9. Suri, K.; Cadavid, J.; Alferez, M.; Dhouib, S.; Tucci-Piergiovanni, S. Modeling Business Motivation and Underlying Processes for RAMI 4.0-Aligned Cyber-Physical Production Systems. In Proceedings of the 22nd IEEE International Conference on Emerging Technologies and Factory Automation, Limassol, Cyprus, 12-15 September 2017; IEEE: New York, NY, USA, 2018. [CrossRef]

10. Global Information Technology Report 2016-Networked Readiness Index. Available online: http://reports. weforum.org/global-information-technology-report-2016/networked-readiness-index/ (accessed on 15 December 2018).

11. Dutta, S.; Lanvin, B.; Wunsch-Vincent, S. Global Innovation Index 2018 Energizing the World with Innovation. Available online: https://www.globalinnovationindex.org/gii-2018-report (accessed on 15 December 2018).

12. Schwab, K. The Global Competitiveness Report 2018; World Economic Forum: Geneva, Switzerland, 2018; Available online: http://www3.weforum.org/docs/GCR2018/05FullReport/ TheGlobalCompetitivenessReport2018.pdf (accessed on 15 December 2018).

13. OECD Science, Technology and Industry Scoreboard 2017: The Digital Transformation; OECD Publishing: Paris, France, 2017. 
14. Siepen, S. Industry 4.0: The role of Switzerland within a European Manufacturing Revolution. Available online: https:/ / www.rolandberger.com/en/Publications/Industry-4.0-The-role-of-Switzerland. html (accessed on 15 December 2018).

15. The Reference Architectural Model Industrie 4.0 (RAMI 4.0). Available online: https://www.zvei.org/ 0en/press-media/publications / the-reference-architectural-model-industrie-40-rami-40/ (accessed on 15 December 2018).

16. Industry 4.0 Component Model-Derived from RAMI 4.0 and Oriented on Information Technology. Available online: https://www.zvei.org/fileadmin/user_upload/Themen/Industrie_4.0/Das_ Referenzarchitekturmodell_RAMI_4.0_und_die_Industrie_4.0-Komponente/pdf/ZVEI-Industrie40-Component-English.pdf (accessed on 15 December 2018).

17. Industry 4.0 Readiness Online Self-Check for Business. Available online: https:/ /www.industrie40-readiness. de/?lang=en (accessed on 15 December 2018).

18. Leyh, C.; Schaffer, T.; Bley, K.; Forstenhausler, S. SIMMI 4.0-A Maturity Model for Classifying the Enterprise-wide IT and Software Landscape Focusing on Industry 4.0. In Proceedings of the Federated Conference on Computer Science and Information Systems (FEDCSIS), Gdansk, Poland, 11-14 September 2016; IEEE: New York, NY, USA, 2016; pp. 1297-1302.

19. Weber, C.; Kongsberger, J.; Kassner, L.; Mitschang, B. M2DDM-A Maturity Model for Data Driven Manufacturing. In Proceedings of the 50th CIRP conference on Manufacturing Systems, Taichung City, Taiwan, 3-5 May 2017; pp. 173-178.

20. Bogner, E.; Voelklein, T.; Schroedel, O.; Franke, J. Study Based Analysis on the Current Digitalisation Degree in the Manufacturing Industry in Germany. Procedia CIRP 2016, 57, 14-19. [CrossRef]

21. Schumacher, A.; Erol, S.; Sihn, W. A Maturity Model for Assessing Industry 4.0 Readiness and Maturity of Manufacturing Enterprises. Procedia CIRP 2016, 52, 161-166. [CrossRef]

22. Jodlbauer, H.; Schagerl, M. Reifegradmodell Industrie 4.0-Ein Vorgehensmodell zur Identifikation von Industrie 4.0 Potentialen. In Proceedings of the INFORMATIK 2016-Informatik von Menschen für Menschen-46th Jahrestagung der Gesellschaft für Informatik, Klagenfurt, Austria, 26-30 September 2016; Mayr, H.C., Pinzger, M., Eds.; Gesellschaft für Informatik: Bonn, Germany, 2016; pp. 1473-1487. (In Germany)

23. Pessl, E.; Romina, S.; Mayer, B. Roadmap Industry 4.0-Implementation Guideline for Enterprises. Int. J. Sci. Technol. Soc. 2017, 5, 193-202. [CrossRef]

24. Back, A.; Berghaus, S. Digital Maturity \& Transformation Studie: Über das Digital Maturity. Available online: https:/ / aback.iwi.unisg.ch/fileadmin/projects/aback/web/pdf/digitalmaturitymodel_download_ v2.0.pdf (accessed on 15 December 2018). (In Germany)

25. De Carolis, A.; Macchi, M.; Negri, E.; Terzi, S. A Maturity Model for Assessing the Digital Readiness of Manufacturing Companies. In Proceedings of the APMS CONFERENCE 2017-Advances in Production Management Systems, Hamburg, Germany, 3-7 September 2017; Springer: Berlin/Heidelberg, Germany, 2017; pp. 13-20.

26. Halenár, I.; Juhasova, B.; Juhas, M. Design of Communication Scheme in a Modern Factory in accordance with the Standard of Industry 4.0. Res. Pap. Slovak Univ. Technol. Bratisl. 2016, 24, 101-109. [CrossRef]

27. Gokalp, E.; Sener, U.; Eren, E. Development of an Assessment Model for Industry 4.0: Industry 4.0-MM. In Proceedings of the 17th International Conference Software Process Improvement and Capability Determination SPICE 2017, Palma de Mallorca, Spain, 4-5 October 2017; pp. 128-142.

28. Agca, O.; Gibson, J.; Godsell, J.; Ignatius, J.; Davies, C.V.; Xu, O. An Industry 4 Readiness Assessment Tool. Available online: https://warwick.ac.uk/fac/sci/wmg/research/scip/industry4report/final_version_of_ i4_report_for_use_on_websites.pdf (accessed on 20 December 2018).

29. Ganzarain, J.; Errasti, N. Three stage maturity model in SME towards Industry 4.0. J. Eng. Manag. 2016, 9, 1119-1128. [CrossRef]

30. Industry 4.0-Enabling Digital Operations Self-Assessment from Price Waterhouse Coopers. Available online: https: / /i4-0-self-assessment.pwc.nl/i40/landing/ (accessed on 20 December 2018).

31. Asset Performance Management Maturity Model. Available online: https://www.capgemini.com/wpcontent/uploads/2017/08/asset_performance_management_maturity_model_paper_web_version.pdf (accessed on 20 December 2018). 
32. The Connected Enterprise Maturity Model-How Ready is Your Company to Connect People, Processes, and Technologies for Bigger Profits? Available online: https:/ / literature.rockwellautomation.com/idc/ groups / literature/documents/wp/cie-wp002_-en-p.pdf (accessed on 20 December 2018).

33. Schuh, G.; Anderl, R.; Gausemeier, J.; ten Hompel, M.; Wahlster, W. (Eds.) Industrie 4.0 Maturity Index. Managing the Digital Transformation of Companies; Herbert Utz Verlag: Munich, Germany, 2017.

34. Průmysl 4.0 a Sebehodnocení Digitální Zralosti Firmy. Available online: http:/ / firma4.cz/ (accessed on 20 December 2018). (In Czech)

35. Pathfinder 4.0-German Innovation Center for Industry 4.0. Available online: https:/ / company.i40.de/en/ consulting/pathfinder-i40 (accessed on 20 December 2018).

36. The Singapore Smart Industry Readiness Index. Available online: https://www.gov.sg/ \{\}/ sgpcmedia/media_releases/edb/press_release/P-20171113-1/attachment/The\%20Singapore\%20Smart\% 20Industry\%20Readiness\%20Index\%20-\%20Whitepaper_final.pdf (accessed on 20 December 2018).

37. Warnecke, H.-J. The Fractal Company-A Revolution in Corporate Culture, 1st ed.; Springer: Berlin/Heidelberg, Germany, 1993.

38. Valenta, F. Inovace v manažerské praxi; Velryba: Prague, Czech Republic, 2001. (In Czech)

39. Marik, V. Průmysl 4.0 Výzva pro Českou Republiku, 1st ed.; Management Press: Prague, Czech Republic, 2016. (In Czech)

40. Felluga, D. General Introduction to Postmodernism. Available online: https://www.cla.purdue.edu/ english/theory/postmodernism/modules/introduction.html (accessed on 20 December 2018).

41. Dastbaz, M.; Pattinson, C.; Akhgar, B. Green Information Technology: A Sustainable Approach, 1st ed.; Morgan Kaufmann Publishers: Waltham, MA, USA, 2015.

(C) 2019 by the authors. Licensee MDPI, Basel, Switzerland. This article is an open access article distributed under the terms and conditions of the Creative Commons Attribution (CC BY) license (http://creativecommons.org/licenses/by/4.0/). 